\title{
Cardiac Resynchronization Therapy Optimization: A Comprehensive Approach
}

\author{
Asim Katbeh ${ }^{a, b}$ Guy Van Camp ${ }^{a}$ Emanuele Barbato ${ }^{a, b}$ Maurizio Galderisi ${ }^{b}$ \\ Bruno Trimarco $^{b}$ Jozef Bartunek ${ }^{a}$ Marc Vanderheyden ${ }^{a}$ Martin Penicka $^{a}$ \\ ${ }^{a}$ Cardiovascular Center Aalst, OLV Clinic, Aalst, Belgium; ${ }^{b}$ Department of Advanced Biomedical Sciences, \\ University of Naples Federico II, Naples, Italy
}

\section{Keywords}

Heart failure - Cardiac dyssynchrony · Myocardial dysfunction - Cardiac resynchronization - Therapy optimization

\begin{abstract}
Since the first report on biventricular pacing in 1994, cardiac resynchronization therapy (CRT) has become standard for patients with advanced heart failure (HF) and ventricular conduction delay. CRT improves myocardial function by resynchronizing myocardial contraction, which results in reverse left ventricular remodeling and improves symptoms and clinical outcomes. Despite the accelerated development of CRT device technology and its increased application in treating $\mathrm{HF}$ patients, almost one-third of these patients do not respond to the therapy or gain any clinical benefit from device implantation. Over the last decade, multiple cardiac imaging modalities have provided a deeper understanding of myocardial pathophysiology, thereby improving HF treatment management. However, the optimal strategy for improving the CRT response remains debatable. This article provides an updated overview of the electropathophysiology of myocardial dysfunction in ventricular conduction delay and the diagnostic approaches involving the use of multiple modalities.
\end{abstract}

(c) 2019 S. Karger AG, Basel

\section{KARGER}

(c) 2019 S. Karger AG, Basel

E-Mail karger@karger.com

www.karger.com/crd

\section{Introduction}

The selection of patients with heart failure (HF) and ventricular conduction delay who will benefit from cardiac resynchronization therapy (CRT) requires both an accurate assessment of myocardial structure and function and a clinical evaluation. According to recent guidelines, patients are considered candidates for CRT if they have HF symptoms of New York Heart Association (NYHA) class II-IV, left ventricular (LV) ejection fraction $(\mathrm{LVEF}) \leq 35 \%$, and a QRS duration $>130 \mathrm{~ms}$ on ECG $[1,2]$. Despite the selection criteria, $30-35 \%$ of patients are nonresponders with no symptomatic improvement or reverse LV remodeling $[3,4]$. Some individuals even experience a clinical deterioration following device implantation [3, 4]. In addition, the parameters used to predict CRT response have not been significantly associated with an increase in the responder rate. Of note, left bundle branch block (LBBB) morphology, a QRS duration of $\geq 150 \mathrm{~ms}$, and adequate coronary sinus anatomy have been most closely associated with a favorable CRT response $[3,4]$; mitral valve regurgitation (MR), right ventricular (RV) dysfunction, and atrial fibrillation (AF) have been shown to have a negative impact on patient response [5-7]. However, all these conditions are highly and concomitantly prevalent in patients undergoing

\footnotetext{
M. Penicka

Cardiovascular Center Aalst, OLV Clinic

Moorselbaan 164

BE-9300 Aalst (Belgium)

E-Mail martin.penicka@olvz-aalst.be
} 
CRT, which makes their use challenging. Finally, CRTdevice programing parameters that delay the progression of myocardial damage have largely remained unidentified.

During the past 2 decades, several echocardiographyor ECG-derived strategies to improve outcomes in CRT patients have been proposed $[8,9]$. However, the exact cut-off values to predict the response and clinical outcome post-CRT are not yet established. Studies are ongoing to improve the role of imaging in predicting CRT response, including EuroCRT, a large European multicenter prospective observational study [10]. Furthermore, several CRT-device programming approaches for CRT optimization have emerged [11]. It has become clear that the development of appropriate strategies to improve CRT response will require answering a range of both clinical and technological questions. Novel bio-imaging markers associated with myocardial function restoration post-CRT are still to be identified and the available CRT technology needs further adjustment. This review provides an updated overview of the pathophysiology of myocardial dysfunction in ventricular conduction delay and the diagnostic approaches for CRT that involve multiple modalities.

\section{Pathophysiology of Myocardial Dysfunction in LV Conduction Delay}

Mechanical contractility is a consequence of electrical activation of the heart. Hence, early detection of abnormal electrical-mechanical patterns is important. LV systolic function is inversely correlated with electrical width and vector of the QRS complex on ECG. However, in clinical practice, electrical reverse remodeling is not always accompanied by mechanical reverse remodeling. Accordingly, CRT optimization focused on achieving the shortest-paced QRS duration has yielded mixed echocardiographic and clinical results [12]. The major determinants of myocardial performance and cardiac output are preload, myocardial contractility, and afterload [13, 14]. In the dyssynchrony pattern, the systolic stretching leaves the septum in a hibernation state characterized by switching metabolism from free fatty acids to glucose as the preferred substrate; consequently, the septum no longer contributes to LV systolic function and stroke volume [15]. The systolic stretching caused by LV free-wall shortening impairs the work performed by the septal segment and the septum absorbs energy. In LBBB, the abnormal early activation may result in a partial or complete loss of sep-

CRT Optimization: A Comprehensive Approach tum contribution. These changes in myocardial function can eventually lead to alterations in adrenergic density as well as the deterioration of the resting function, inotropic reserve, and function recovery [16]. In HF patients with ventricular conduction delay, impaired LV function has been considered a reversible process which can be improved by restoring the myocardial function using CRT, but the most favorable effects are observed in patients with significant myocardial viability and contractile reserve. Such patients have the potential to improve after CRT therapy $[15,17]$.

\section{Patterns of Motion and Deformation}

In patients with $\mathrm{LBBB}$, the apex exhibits a pre-ejection rocking motion, due to active septal contraction unopposed by the absence of activation of LV lateral wall contraction. Many researchers suggested using visual markers of cardiac motion including apical rocking and septal flash as indicators for dyssynchrony $[18,19]$. However, dyssynchrony is often subtle, and so it cannot be quantified by visual assessment alone. Quantitative tools should be used to complement the visual description of myocardial deformation [18-20].

Since 2002, cardiac motion dyssynchrony has traditionally been described by parameters such as a septal-toposterior wall motion delay $\geq 130 \mathrm{~ms}$ measured by $\mathrm{M}$ mode echocardiography [21]. More recently, myocardial deformation has been assessed by imaging tools such as color-coded or pulsed tissue Doppler imaging, with dyssynchrony indicated by an opposing wall delay of $\geq 65 \mathrm{~ms}$ and a time to onset systolic velocity of $\geq 100 \mathrm{~ms}$. However, these indicators have many technical limitations [21].

Speckle-tracking echocardiography (STE) imaging applied to routine echocardiography can provide higher accuracy to predict reverse LV remodeling post-CRT, as defined by an acute improvement of LVEF or LV endsystolic volume [22]. An acute increase in magnitude, together with more extensive synchronization of LV longitudinal strain, has been associated with improved functional capacity and NYHA class post-CRT [23]. This finding supports the use of STE to assess global longitudinal and radial strains to predict the extent of reverse LV remodeling following CRT (Fig. 1). Furthermore, regional strain patterns, particularly of septal strain, may help in assessing myocardial deformation in dyssynchronous $\mathrm{HF}$, although the extent of acute change that predicts the clinical outcome remains unknown $[24,25]$. 


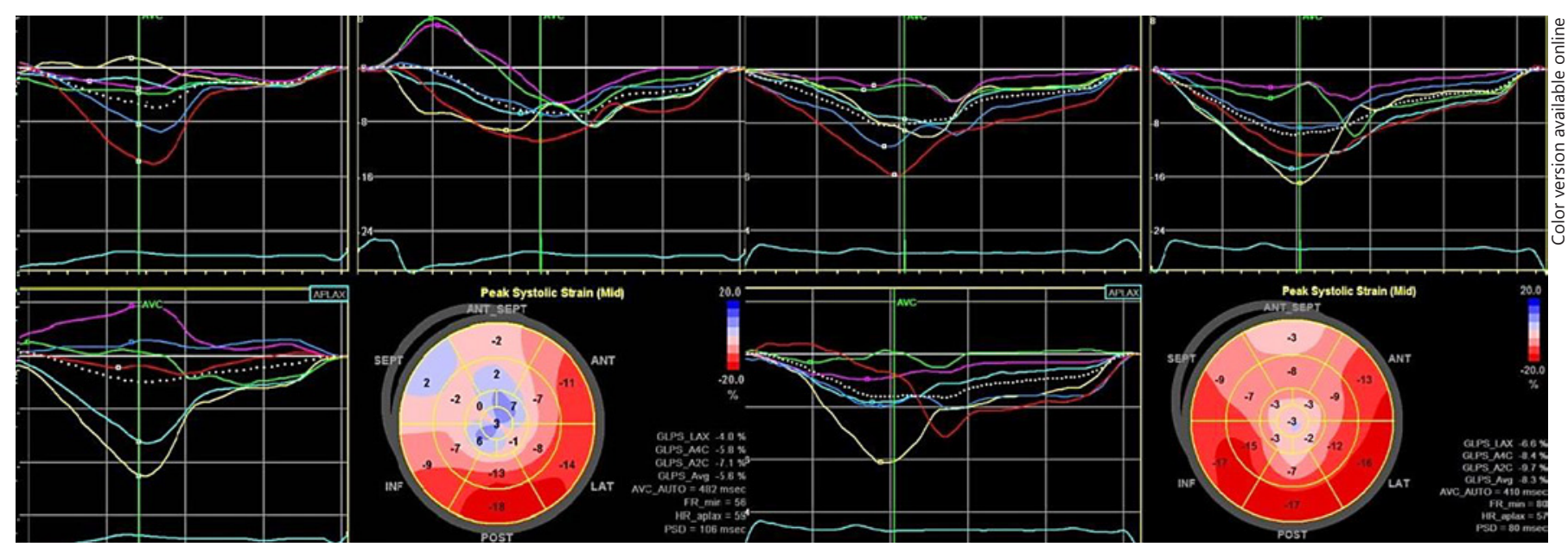

Fig. 1. Speckle-tracking echocardiography showing global longitudinal strain of the left ventricle in a patient with heart failure treated by cardiac resynchronization therapy (CRT). Left, before implanting CRT; right, echocardiography-based CRT optimization at 3 months.

Tissue tracking by using cine cardiac magnetic resonance (cine-CMR) has shown promising results, with recent studies reporting comparable results for radial dyssynchrony between cine-CMR and STE [26]; CMR can also be used to identify and evaluate mechanical dyssynchrony in patients with LBBB [27]. However, CMR has technical limitations in HF patients with LBBB, and further evaluation is needed before it can be clinically implemented [27]. Other limitations are high costs and limited availability.

\section{Myocardial Viability and Fibrosis}

CRT response may be reduced by diminished myocardial viability associated with extensive LV scarring [28]. Moreover, CRT electrodes should not be placed in segments with scar tissue which can be easily identified on CMR $[29,30]$. Patients with ischemic LV dysfunction and LBBB may have various amounts of focal myocardial fibrosis including in the interventricular septum. In contrast, patients with nonischemic cardiomyopathy may have a high level of diffuse fibrosis in the septum. A detailed description of regional myocardial fibrosis in dyssynchrony is needed (Fig. 2).

Advanced imaging methods, such as CMR, allow quantitative assessment of focal and diffuse myocardial fibrosis, but they do have limitations. CMR with late gadolinium enhancement, in particular, shows wide variation in quantifying focal fibrosis and cannot detect diffuse fibrosis [31, 32]. Other CMR approaches, such as T1 map- ping and extracellular volume mapping, are affected by specific CMR techniques and magnetic field strength; they lack reference ranges, and there is a significant overlap of T1 mapping values of healthy and disease states $[31,32]$.

Using innovative imaging tools in this field is key to understanding the disease of the myocardial muscle, in terms of cellular and tissue abnormalities. Nuclear imaging, including positron emission tomography (PET), demonstrates reduced myocardial perfusion, glucose uptake, and oxidative metabolism in the septum of LBBB patients [33]. CRT partially normalizes these changes; therefore, measuring these radionuclide parameters may offer an improved approach for selecting CRT candidates [33]. Similarly, single-photon emission computed tomography (CT) supplies information about perfusion and is complementary to PET, which reflects metabolism. Radiation dose and the limited availability of PET may hamper routine clinical use. The advantages and limitations of different imaging techniques are summarized in Table 1.

\section{Concomitant Cardiac Conditions}

$\mathrm{RV}$ dysfunction is associated with a poor prognosis for HF patients [34]. Its role in CRT candidates is controversial. Impaired RV function pre-CRT, similar to HF, is associated with worse survival post-CRT [35], but a study has shown that CRT may improve RV function and prognosis in patients with RV dysfunction [36]. A previous 
Fig. 2. Examples of resting global longitudinal strain (GLS) of the left ventricle compared with the extent of hypoperfusion and the distribution of myocardial fibrosis in a patient with complete left bundle branch block and significantly reduced biventricular function. a Late gadolinium enhancement on cardiac magnetic resonance imaging demonstrating a dense septal scar in the left ventricular septal wall. b Scintigraphy image of a very large area of severe myocardial hypoperfusion and extensive transmural infarction in the septum. c, d Tissue Doppler image of myocardial dyssynchrony with a reduced magnitude of $2 \mathrm{D}$ GLS measured by speckle-tracing echocardiography.
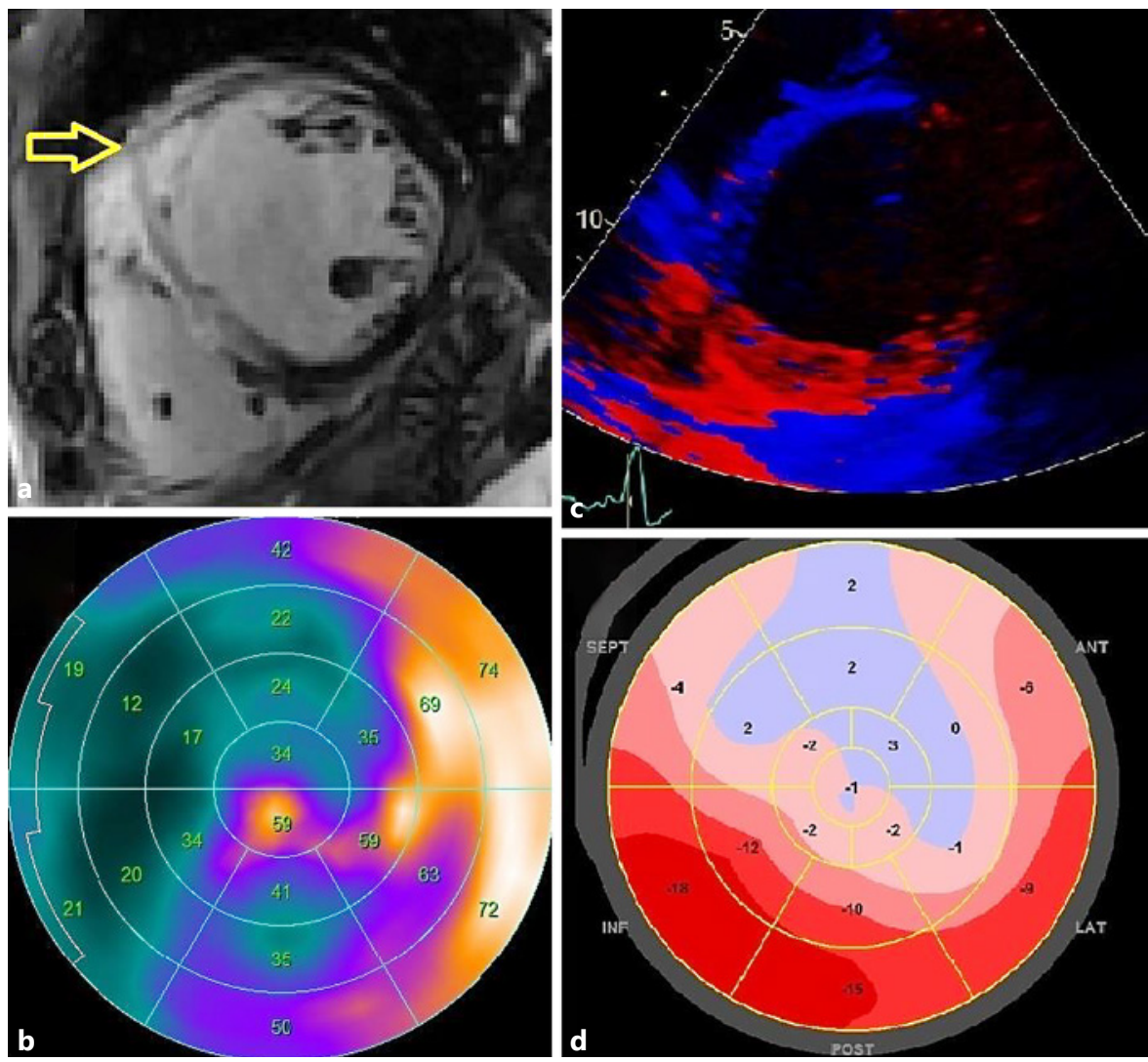

Table 1. Cardiovascular imaging modalities and their advantages and limitations for the selection of cardiac resynchronization therapy candidates and optimizing therapy

\begin{tabular}{|c|c|c|}
\hline & Advantages & Limitations \\
\hline Echocardiography & Widely used; safe after CRT implantation & $\begin{array}{l}\text { Relative subjectivity in quantifying } \\
\text { myocardial dynamics }\end{array}$ \\
\hline Tissue tracking with STE & $\begin{array}{l}\text { Non-Doppler angle-independent evaluation of myocardial } \\
\text { deformation evaluation; good reproducibility }\end{array}$ & $\begin{array}{l}\text { Tracking affected by out-of-plane } \\
\text { cardiac motion; intervendor variability }\end{array}$ \\
\hline CMR mapping & $\begin{array}{l}\text { More objective quantification of myocardial systolic } \\
\text { dynamics; LGE and T1 mapping are promising methods for } \\
\text { detecting focal and diffuse myocardial fibrosis, respectively }\end{array}$ & $\begin{array}{l}\text { High cost and limited availability; } \\
\text { adverse reaction to gadolinium; relative } \\
\text { complexity of acquisition }\end{array}$ \\
\hline Tissue tracking with CMR & $\begin{array}{l}\text { Imaging possible in any plane; complete myocardium } \\
\text { visualization }\end{array}$ & $\begin{array}{l}\text { Technical limitations in HF patients } \\
\text { with LBBB; time-consuming }\end{array}$ \\
\hline PET and SPECT & $\begin{array}{l}\text { Complementary assessment of CRT candidate with ischemic } \\
\text { cardiomyopathy }\end{array}$ & Not widely used \\
\hline X-ray fluoroscopy & $\begin{array}{l}\text { Guides the position of the CRT leads by contrast injection } \\
\text { through the right heart cavity and coronary sinus }\end{array}$ & $\begin{array}{l}\text { Limited used for guiding the CRT leads } \\
\text { during the procedure }\end{array}$ \\
\hline MSCT & $\begin{array}{l}\text { Visualization of cardiac veins; evaluation of structural } \\
\text { remodeling in patients with inadequate echocardiographic } \\
\text { images and CMR contraindications }\end{array}$ & High radiation dose \\
\hline
\end{tabular}

CRT, cardiac resynchronization therapy; STE, speckle-tracking echocardiography; CMR, cardiac magnetic resonance; LGE, late gadolinium enhancement; HF, heart failure; LBBB, left bundle branch block; PET, positron emission tomography; SPECT, single-photon emission computed tomography; MDCT, multidetector computed tomography. 
meta-analysis revealed that echocardiographic parameters of RV function do not predict CRT response-related changes in LVEF [37]. In contrast, a recent study reported that RV systolic dysfunction before CRT implantation could identify patients that might not benefit from CRT [38], and a prospective study concluded that CRT induces RV reverse remodeling and improves RV function with improved interventricular dependence [39]. Furthermore, a higher baseline RV-pulmonary artery (PA) coupling is associated with improved LV reverse remodeling and independently associated with a better prognosis [40]. Of note, the response to CRT was strongly associated with RV-PA coupling in both studies $[39,40]$. However, using the RV-to-PA ratio as a potential guide for CRT in patients with diseases in whom RV failure predominates needs further investigation $[39,40]$.

Patients with congenital heart disease (CHD) may benefit from CRT. A recent German registry revealed that CRT can be used as an adjunct in the HF treatment of selected CHD patients [41]. A retrospective review on 20 patients with congenitally corrected transposition of the great arteries reported that CRT implantation is feasible, and that the long-term outcome is favorable but linked to systematic morphologic RV dysfunction in some patients [42]. Since most of the studies available are retrospective in nature, the impact of CRT on long-term prognosis in this population is still unknown [43,44].

Several studies have shown that CRT improves secondary MR $[45,46]$. A less favorable effect on MR has been reported in ischemic LV dysfunction with extensive scarring. Larger residual MR (an effective orifice area $\geq 0.20 \mathrm{~cm}^{2}$ ) following CRT has been associated with increased mortality and HF hospitalizations [47]. A recent study on 277 HF patients observed that MR severity at 6 months decreased in 48 (42\%), remained stable in 42 $(37 \%)$, and worsened in 24 (21\%). Four-year adverse event rates were strongly predicted by the presence of at least moderate MR after, but not before, CRT [48]. On the other hand, a prospective study on 198 patients demonstrated that significant secondary MR after CRT is associated with higher morbidity and mortality, i.e., MR despite CRT provides important prognostic information beyond LV reverse remodeling [49].

Patients with AF before and after CRT represent a challenging cohort with insufficient data to guide clinical decision-making. CRT is recommended in patients with $\mathrm{AF}$ and $\leq 35 \mathrm{LVEF}$ who meet the CRT criteria and in whom atrioventricular (AV) node ablation or pharmacological rate control allow approximately $100 \%$ ventricular pacing with CRT [50]. Although CRT improves some risk factors for AF, such as atrial size and LV systolic function, it does not reduce AF recurrence [50]. It is of note that, in HF with AF, pulmonary vein isolation may result in a better control of symptoms at short-term follow-up compared than CRT plus AV node ablation [51]. However, because the long-term effects remain unknown, pulmonary vein isolation should be only performed in selected individuals, taking into account patients' preference [51]. Further data on these patients are needed for developing a standardized approach.

\section{Noncardiac Comorbidities}

Many noncardiac comorbidities, e.g., diabetes, hypertension, dyslipidemia, obesity, respiratory insufficiency, and renal dysfunction, negatively affect myocardial contractility. CRT response is associated with the stabilization or improvement of renal function, which, in turn, is associated with lower mortality $[52,53]$. A meta-analysis suggested that diabetic patients with advanced HF who received CRT exhibited higher total mortality than nondiabetic patients [54]. However, the increased mortality might have been attributable to insulin administration [54]. In the same context, another retrospective analysis showed that coexisting chronic obstructive pulmonary disease was an independent predictor of a nonresponse to CRT [55]. Cardiac disease but also noncardiac concomitant diseases should be taken into consideration when selecting patients for CRT [56].

\section{Blood Biomarkers}

Blood biomarkers, such as N-terminal pro-B-type natriuretic peptide (NT-proBNP), troponin T, galectin-3, and plasma miRNA-21, reflect myocardium status in HF patients. A reduction in the levels of these markers is mostly associated with a favorable CRT response [57]. The BIOCRT study revealed that NT-proBNP levels were $20 \%$ higher in the coronary sinus than in the peripheral veins [58]. It suggested that the coronary sinus sampling of HF biomarkers is more accurate than the peripheral venous blood sampling for predicting CRT outcomes. This study also reported that elevated galectin-3 levels during CRT device implantation are associated with the absence of MR improvement after CRT [59]. Thus, high circulating levels of these markers at the coronary sinus or peripheral veins may predict the CRT response and could therefore be used to document therapy success. 


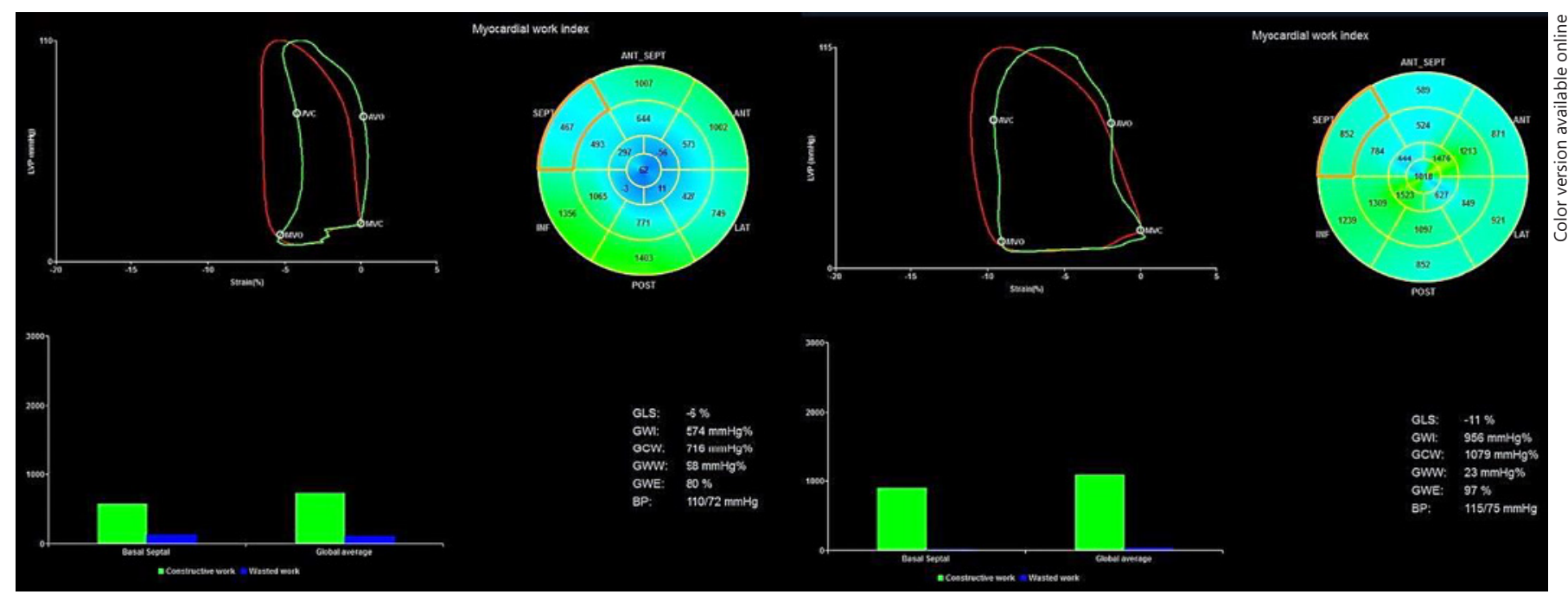

Fig. 3. Regional and global myocardial work in a heart failure patient responded to cardiac resynchronization therapy (CRT). Left, before implanting CRT; regional work was inhomogeneous in the septal segments. Right, after 12 months; CRT increases the global myocardial work and this inhomogeneity disappeared.

\section{AV and Ventriculoventricular Time Interval}

Prolonged PR intervals may impair AV mechanical coupling and the restoration of AV mechanical coupling with CRT may improve survival [60]. Following CRT implantation, AV interval optimization is of crucial importance to allow the completion of the atrial contribution to diastolic filling, resulting in the most favorable preload before ventricular contraction [61]. Several approaches have been used to optimize AV time interval. The CRT device's AV interval time setting has been considered the cornerstone for restoring myocardial contractility and performance. Doppler echocardiography-derived AV optimization has been associated with an improvement in both LV systolic function and presystolic MR. In brief, $\mathrm{AV}$ delay is programmed so that the end of atrial contraction is timed to coincide with the onset of ventricular contraction [62]. Because AV dyssynchrony is common and modifiable, Doppler echocardiography-guided AV optimization after CRT is warranted, particularly in nonresponders with a fused or truncated LV filling pattern [63]. The clinical efficacy of AV optimization has yet to be established.

The ventriculoventricular (VV) interval optimization, which is affected by LV and RV function, is rarely performed because it is time-consuming and without proven clinical benefit [64]. The methods used for VV optimization may be suboptimal to achieve adequate inter- and intraventricular resynchronization. However, it is still necessary to demonstrate its clinical relevance, and VV interval modification may be proposed to reduce the persistent asynchrony in nonresponders [65]. In summary, in clinical practice, CRT system parameters are often set empirically, using a shortened AV interval (90-120 ms) and simultaneous biventricular (BiV) pacing, with no further optimization during follow-up.

\section{Mechanical Work}

To assess myocardial reverse remodeling which directly affects the cardiac output following CRT, previously, studies used simple visual patterns such as apical rocking and septal flash to predict CRT responders $[19,20,66]$. Furthermore, it was reported that the correction of mechanical dyssynchrony versus the volumetric response was associated with long-term survival [67]. Recently, the calculation of the systolic dyssynchrony index (SDI) via real-time 3D echocardiography showed a superiority in the assessment of LV performance following CRT [68]. In contrast to a previous small study which reported that CRT optimization of interventricular delay by using SDI (vs. QRS width) assessment did not reveal any significant difference in terms of volumetric and clinical response at the 12-month follow-up [69], recent large studies have demonstrated that a more pronounced reduction in SDI immediately after CRT is independently associated with a superior long-term outcome [70], and that SDI derived 
Table 2. Echocardiography-based cardiac resynchronization therapy candidate selection criteria and response optimization

\begin{tabular}{lll}
\hline Method & Useful markers and parameters & Comments \\
\hline M-mode & Septal-to-posterior wall motion delay of $\geq 130 \mathrm{~ms}$ & Limited assessment in clinical practice \\
\hline B-mode & $\begin{array}{l}\text { LVEF improvement and } \geq 15 \% \text { ESV reduction } \\
\text { relative to baseline }\end{array}$ & $\begin{array}{l}\text { Standard parameters for predicting } \\
\text { CRT response }\end{array}$ \\
\hline Color-coded tissue Doppler imaging & Opposing wall delay of $\geq 65 \mathrm{~ms}$ & Many technical limitations \\
\hline Pulsed tissue Doppler imaging & Delay in time-to-onset systolic velocity of $\geq 100 \mathrm{~ms}$ & Many limitations \\
\hline $\begin{array}{l}\text { Standard views based on LV } \\
\text { mechanical description }\end{array}$ & $\begin{array}{l}\text { Apical rocking and septal flash introduced to } \\
\text { describe myocardial dyssynchrony }\end{array}$ & Relatively subjective \\
\hline STE-derived strain & $\begin{array}{l}\text { STE-derived regional strain and global strain } \\
\text { measurement to determine LV reverse remodeling }\end{array}$ & $\begin{array}{l}\text { Non-Doppler; angle-independent; } \\
\text { underutilized }\end{array}$ \\
\hline Area tracking using 3D STE & $\begin{array}{l}\text { Area strain dyssynchrony index may enable a more } \\
\text { objective quantification of myocardial systolic } \\
\text { dynamics }\end{array}$ & $\begin{array}{l}\text { Good image quality required for 3D } \\
\text { STE; debatable STE standardization }\end{array}$ \\
\hline $\begin{array}{l}\text { Assessment of wasted myocardial } \\
\text { work }\end{array}$ & $\begin{array}{l}\text { Pressure-strain loops describe strain dispersion } \\
\text { due to load change }\end{array}$ & Further investigation required \\
\hline
\end{tabular}

CRT, cardiac resynchronization therapy; LVEF, left ventricular ejection fraction; ESV, end-systolic volume; LV, left ventricular; STE, speckle-tracking echocardiography.

by $3 \mathrm{D}$ speckle-area tracking shows a good correlation with the reduction of end-systolic volume post-CRT [71]. However, there is no consensus regarding the feasibility of using SDI to optimize the CRT.

Recently, noninvasive methods of calculating myocardial work have been applied in research into CRT response. Recent studies focused on mechanical dyssynchrony by taking into account the wasted and constructive myocardial work by means of strain analyses and hemodynamic data $[72,73]$. The assessment of regional distribution to myocardial work based on different hemodynamics patterns can be used to determine the impact of elevated load on myocardial performance in HF patients that qualify for CRT [74]. These myocardial work indices derived from pressure-strain loops may provide comparable beneficial effects to serial evaluation of LV function (Fig. 3). At present, it is reasonable to consider these indices as semiquantitative novel tools to aid in guiding CRT, but caution is needed until this is validated in larger prospective studies. Echocardiography-based CRT candidate selection criteria and response optimization are summarized in Table 2.

The assessment of BiV performance by echocardiography stress test should be interpreted to identify pathways and targets, so that we can address different phase patterns of ventricular remodeling and determine the de- gree of residual dyssynchrony, particularly in nonresponders [75]. On the other hand, cardiopulmonary exercise testing (CPET) might be helpful to assess the exercise capacity of HF patients with diseases of heart muscle and other significant diseases underestimated by rest evaluation [76]. Contemporary trends suggest that combined CPET imaging stress test can be implemented in clinical practice to assess $\mathrm{BiV}$ dysfunction in different $\mathrm{HF}$ phenotypes not detectable with rest evaluation [77].

\section{Lead Placement}

Optimal LV lead placement is crucial for a favorable CRT response. Accumulated evidence suggested that mechanical resynchronization is the primary mechanism underlying CRT response. Accordingly, in the absence of scarring, the optimal LV lead position is generally lateral or posterolateral because this is often the latest segment to contract in the presence of LBBB [78]. In contrast, apical pacing and pacing in a densely scarred region should be avoided when tailoring the therapy and to prevent adverse events $[78,79]$. A multimodality complementary approach is ideal to establish the optimal CRT lead placement precisely. Multidetector CT can be used for preoperative mapping of the cardiac veins to assess 
the availability of suitable veins in potential target segments prior to CRT implantation [80]. The CRT outcome can be predicted by analyzing the $3 \mathrm{D}$ coronary sinus lead-tip trajectory and optimizing its placement based on advanced imaging methods [81]. Clearly, the introduction of a LV quadripolar lead provides multiple ways to pace the ventricle, and thus more options to avoid negative workload of the LV segments and achieve CRT optimization [82].

Maximal electric separation-guided placement of the RV defibrillation lead during CRT should be considered. The results of recent studies clearly show the benefits, in terms of reverse LV remodeling and clinical response, that can be obtained with optimization of the RV lead pacing position; the placement of the RV lead guided by maximal electric separation compared with standard apical placement not only improves cardiac function but can also reduce the risk of ventricular arrhythmia $[83,84]$. For CRT therapy, multipoint pacing, guided by noninvasive hemodynamics, shows a positive LV structural remodeling [85]. However, many limitations in LV lead implantation, due to anatomical or other constraints, need to be considered. At present, permanent His-bundle pacing is a feasible alternative for patients in whom BiV pacing provided no clinical response. His-bundle pacing allows for the recruitment of $\mathrm{BBB}$ disease and ventricular activation in a more physiological fashion, specifically in patients with right $\mathrm{BBB}$ and those with AV block [86].

\section{Emerging Optimization Strategy}

A timely upgrade to $\mathrm{BiV}$ - or His-bundle-pacing devices needs to be considered in patients with CRT. A single-center registry involving 304 patients demonstrated that daily remote monitoring can be useful to identify the percentage of $\mathrm{BiV}$ pacing, and that a higher percentage improves the long-term prognosis after CRT [87]. Moreover, a recent study including 201 candidates reported that a higher percentage of $\mathrm{BiV}$ pacing ( $>98 \%$ at 6 months after CRT) is essential for patients to become superresponders [88]. However, the real clinical value of $\mathrm{BiV}$ pacing percentage still needs to be validated in multicenter prospective studies.

Sensor-derived approaches are rapidly developing in modern cardiology. In CRT patients, the SonR sensor, which is embedded in the right atrial lead and picks up the intensity of the first heart sound as a surrogate for cardiac contractility, has been used to optimize CRT settings [89]. It provides the opportunity for continuous reading

CRT Optimization: A Comprehensive Approach of myocardial contractility during rest and exercise. This allows continuous adaptation of the AV and VV interval setting of the CRT device according to the instantaneous needs of the patient [89]. A comparative study demonstrated that automatic optimization with the SonR sensor is as effective as echo-guided optimization, allowing the primary efficacy end point to be met with a $35 \%$ significant reduction in HF hospitalization rates during longterm follow-up [90].

\section{Advanced Computer Modeling}

Advanced computer modeling combined with machine learning may provide mechanistic insights into CRT efficacy. It may help to solve complex problems involving big data by identifying interaction patterns among multiple variables in potential CRT candidates [91, 92]. The application of neural networks and deep learning in cardiovascular medicine plays a crucial role in imaging accusation, reconstruction, quantification, and analysis [93]. A combined deep-learning and deformable-model approach is a promising tool for fully automatic segmentation of the myocardium in CMR [94].

Thanks to recent advances in addictive manufacturing technologies, computational modeling and 3D printing have become powerful tools to describe the heart structure and the properties of myocardial tissue [95]. The encouraging results highlight clinical perspectives on the use of computer-aided design models to monitor myocardial structural changes following CRT and ultimately shape a favorable remodeling response to CRT $[96,97]$. Certainly, the integration of imaging and nonimaging information based on computer-aided diagnosis will allow us to determine not only the effect of CRT on myocardial performance in the different phenotypes of cardiomyopathy, but also the long-term impact of CRT on the different symptomatic classes of HF patients [98].

\section{Conclusion}

CRT has shown significant clinical benefits for patients with HF refractory to medical therapy. Despite the great advances in CRT technology over the past decade, a further improvement of device settings, lead placement, and imaging tools is needed to improve the efficacy of CRT. However, programming devices to optimize the delivery of CRT remains challenging, and there are still no parameters that are routinely indicated to predict CRT 
response or guide CRT optimization. At present, multivariate computational models are promising tools used in the assessment of electromechanical dyssynchrony, and the latent strength of these methods to optimize CRT has shown great promise. Future advances will hopefully facilitate the identification of new bio-imaging markers and technical approaches to increase the responder rate. The promising results of pilot studies to date need to be validated in a multicenter, prospective setting.

\section{Disclosure Statement}

There were no conflicts of interest.

\section{Funding Sources}

Dr. Katbeh was supported by a research grant from the International $\mathrm{PhD}$ programme in Cardiovascular Pathophysiology and Therapeutics (CardioPaTh).

\section{References}

1 Brignole M, Auricchio A, Baron-Esquivias G, Bordachar P, Boriani G, Breithardt OA, et al.; Document Reviewers. 2013 ESC Guidelines on cardiac pacing and cardiac resynchronization therapy: the Task Force on cardiac pacing and resynchronization therapy of the European Society of Cardiology (ESC). Developed in collaboration with the European Heart Rhythm Association (EHRA). Eur Heart J. 2013 Aug;34(29):2281-329.

2 Epstein AE, DiMarco JP, Ellenbogen KA, Estes NA 3rd, Freedman RA, Gettes LS, et al. 2012 ACCF/AHA/HRS focused update incorporated into the ACCF/AHA/HRS 2008 guidelines for device-based therapy of cardiac rhythm abnormalities: a report of the American College of Cardiology Foundation/American Heart Association Task Force on Practice Guidelines and the Heart Rhythm Society. J Am Coll Cardiol. 2013 Jan;61(3):e6-75.

3 Goldenberg I, Kutyifa V, Klein HU, Cannom DS, Brown MW, Dan A, et al. Survival with cardiac-resynchronization therapy in mild heart failure. N Engl J Med. 2014 May; 370(18):1694-701.

4 Jarcho JA. Biventricular pacing. N Engl J Med. 2006;355(3):288-94.

5 Upadhyay GA, Chatterjee NA, Kandala J, Friedman DJ, Park MY, Tabtabai SR, et al. Assessing mitral regurgitation in the prediction of clinical outcome after cardiac resynchronization therapy. Heart Rhythm. 2015 Jun; 12(6):1201-8.

6 Leong DP, Höke U, Delgado V, Auger D, Witkowski T, Thijssen J, et al. Right ventricular function and survival following cardiac resynchronisation therapy. Heart. 2013 May; 99(10):722-8.

7 Barold SS, Herweg B. Cardiac resynchronization in patients with atrial fibrillation. J Atr Fibrillation. 2015 Dec;8(4):1383

8 Gorcsan J 3rd, Abraham T, Agler DA, Bax JJ, Derumeaux G, Grimm RA, et al.; American Society of Echocardiography Dyssynchrony Writing Group. Echocardiography for cardiac resynchronization therapy: recommendations for performance and reporting-a report from the American Society of
Echocardiography Dyssynchrony Writing Group endorsed by the Heart Rhythm Society. J Am Soc Echocardiogr. 2008 Mar;21(3): 191-213.

9 Assadian Rad M, Tabarzan Baboli N, Barzigar A, Keirkhah J, Soltanipour S, Bonakdar HR, et al. The role of the fragmented QRS complexes on a routine 12-lead ECG in predicting nonresponsiveness to cardiac resynchronization therapy. Anatol J Cardiol. 2015 Mar;15(3): 204-8.

10 Donal E, Delgado V, Magne J, BucciarelliDucci C, Leclercq C, Cosyns B, et al. Rational and design of EuroCRT: an international observational study on multi-modality imaging and cardiac resynchronization therapy. Eur Heart J Cardiovasc Imaging. 2017 Oct;18(10): $1120-7$.

11 Kloppe A, Lemke B, Zarse M. New technologies in the optimization of CRT programming. Herzschrittmacherther Elektrophysiol. 2008 Mar; 19(1):19-29. German.

12 Exner DV, Auricchio A, Singh JP. Contemporary and future trends in cardiac resynchronization therapy to enhance response. Heart Rhythm. 2012 Aug;9(8 Suppl):S27-35.

13 Chiariello M, Perrone-Filardi P. Pathophysiology of heart failure. Miner Electrolyte Metab. 1999 Jan-Apr;25(1-2):6-10.

14 Gjesdal O, Remme EW, Opdahl A, Skulstad H, Russell K, Kongsgaard E, et al. Mechanisms of abnormal systolic motion of the interventricular septum during left bundlebranch block. Circ Cardiovasc Imaging. 2011 May;4(3):264-73.

15 Thompson K, Saab G, Birnie D, Chow BJ, Ukkonen $\mathrm{H}$, Ananthasubramaniam $\mathrm{K}$, et al. Is septal glucose metabolism altered in patients with left bundle branch block and ischemic cardiomyopathy? J Nucl Med. 2006 Nov; 47(11):1763-8

16 Smiseth OA, Remme EW. Regional left ventricular electric and mechanical activation and relaxation. J Am Coll Cardiol. 2006 Jan; 47(1):173-4.

17 Riedlbauchová L, Brunken R, Jaber WA, Popová L, Patel D, Lánská V, et al. The impact of myocardial viability on the clinical outcome of cardiac resynchronization therapy. J Cardiovasc Electrophysiol. 2009 Jan;20(1):50-7.

18 Szulik M, Tillekaerts M, Vangeel V, Ganame J, Willems R, Lenarczyk R, et al. Assessment of apical rocking: a new, integrative approach for selection of candidates for cardiac resynchronization therapy. Eur J Echocardiogr. 2010 Dec;11(10):863-9.

19 Haugaa KH, Edvardsen T, Smiseth OA. Mechanical dyssynchrony-resurrected as a flashing and rocking parameter to predict prognosis after cardiac resynchronization therapy. Eur Heart J Cardiovasc Imaging. 2017 Oct; 18(10):1118-9.

20 Beela AS, Ünlü S, Duchenne J, Ciarka A, Daraban AM, Kotrc M, et al. Assessment of mechanical dyssynchrony can improve the prognostic value of guideline-based patient selection for cardiac resynchronization therapy. Eur Heart J Cardiovasc Imaging. 2019 Jan; 20(1):66-74.

21 Gorcsan J 3rd, Abraham T, Agler DA, Bax JJ, Derumeaux G, Grimm RA, et al.; American Society of Echocardiography Dyssynchrony Writing Group. Echocardiography for cardiac resynchronization therapy: recommendations for performance and reporting-a report from the American Society of Echocardiography Dyssynchrony Writing Group endorsed by the Heart Rhythm Society. J Am Soc Echocardiogr. 2008 Mar;21(3):191-213.

22 Seo Y, Ishizu T, Machino-Ohtsuka T, Yamamoto M, Machino T, Kuroki K, et al. Incremental Value of Speckle Tracking Echocardiography to Predict Cardiac Resynchronization Therapy (CRT) Responders. J Am Heart Assoc. 2016 Oct;5(10):e003882.

23 Khan SG, Klettas D, Kapetanakis S, Monaghan MJ. Clinical utility of speckle-tracking echocardiography in cardiac resynchronisation therapy. Echo Res Pract. 2016 Mar;3(1):R111.

24 van Everdingen WM, Paiman ML, van Deursen CJ, Cramer MJ, Vernooy K, Delhaas T, et al. Comparison of septal strain patterns in dyssynchronous heart failure between speckle tracking echocardiography vendor systems. J Electrocardiol. 2015 Jul-Aug;48(4):609-16. 
25 Cvijic M, Duchenne J, Ünlü S, Michalski B, Aarones M, Winter S, et al. Timing of myocardial shortening determines left ventricular regional myocardial work and regional remodelling in hearts with conduction delays. Eur Heart J Cardiovasc Imaging. 2018 Aug; 19(8):941-949.

26 Onishi T, Saha SK, Ludwig DR, Onishi T, Marek JJ, Cavalcante JL, et al. Feature tracking measurement of dyssynchrony from cardiovascular magnetic resonance cine acquisitions: comparison with echocardiographic speckle tracking. J Cardiovasc Magn Reson. 2013 Oct; 15(1):95.

27 Revah G, Wu V, Huntjens PR, Piekarski E, Chyou JY, Axel L. Cardiovascular magnetic resonance features of mechanical dyssynchrony in patients with left bundle branch block. Int J Cardiovasc Imaging. 2016 Sep; 32(9):1427-38.

28 Ono S, Nohara R, Kambara H, Okuda K, Kawai C. Regional myocardial perfusion and glucose metabolism in experimental left bundle branch block. Circulation. 1992 Mar; 85(3):1125-31.

29 Adelstein EC, Saba S. Scar burden by myocardial perfusion imaging predicts echocardiographic response to cardiac resynchronization therapy in ischemic cardiomyopathy. Am Heart J. 2007 Jan;153(1):105-12.

30 Sweeney MO, van Bommel RJ, Schalij MJ, Borleffs CJ, Hellkamp AS, Bax JJ. Analysis of ventricular activation using surface electrocardiography to predict left ventricular reverse volumetric remodeling during cardiac resynchronization therapy. Circulation. 2010 Feb;121(5):626-34.

31 Everett RJ, Stirrat CG, Semple SI, Newby DE, Dweck MR, Mirsadraee S. Assessment of myocardial fibrosis with T1 mapping MRI. Clin Radiol. 2016 Aug;71(8):768-78.

32 Krombach GA, Niendorf T, Günther RW, Mahnken AH. Tissue characterization of the myocardium: state of the art characterization by MR and CT imaging. Radiol Clin North Am. 2015 Mar;53(2):413-23.

33 Ukkonen H, Beanlands RS, Burwash IG, de Kemp RA, Nahmias C, Fallen E, et al. Effect of cardiac resynchronization on myocardial efficiency and regional oxidative metabolism. Circulation. 2003;107(1):28-31.

34 Sharma A, Bax JJ, Vallakati A, Goel S, Lavie CJ, Kassotis J, et al. Meta-analysis of the relation of baseline right ventricular function to response to cardiac resynchronization therapy. Am J Cardiol. 2016 Apr;117(8):131521.

35 Scuteri L, Rordorf R, Marsan NA, Landolina M, Magrini G, Klersy C, et al. Relevance of echocardiographic evaluation of right ventricular function in patients undergoing cardiac resynchronization therapy. Pacing Clin Electrophysiol. 2009 Aug;32(8):1040-9.

36 Damy T, Ghio S, Rigby AS, Hittinger L, Jacobs $\mathrm{S}$, Leyva $\mathrm{F}$, et al. Interplay between right ventricular function and cardiac resynchronization therapy: an analysis of the CARE-HF tri- al (Cardiac Resynchronization-Heart Failure). J Am Coll Cardiol. 2013 May;61(21): 2153-60.

37 Sharma A, Bax JJ, Vallakati A, Goel S, Lavie CJ, Kassotis J, et al. Meta-Analysis of the Relation of Baseline Right Ventricular Function to Response to Cardiac Resynchronization Therapy. Am J Cardiol. 2016 Apr;117(8): 1315-21.

38 Abdelhamid MA, Ghanem MT, Abdelmotaleb AM. Assessment of right ventriclular systolic function prior to cardiac resynchronization therapy: does it make any difference? Indian Heart J. 2017 Nov - Dec;69(6):731-5.

39 Schmeisser A, Rauwolf T, Ghanem A, Groscheck T, Adolf D, Grothues F, et al. Right heart function interacts with left ventricular remodeling after CRT: A pressure volume loop study. Int J Cardiol. 2018 Oct;268:15661.

40 Martens P, Verbrugge FH, Bertrand PB, Verhaert D, Vandervoort P, Dupont M, et al. Effect of Cardiac Resynchronization Therapy on Exercise-Induced Pulmonary Hypertension and Right Ventricular-Arterial Coupling. Circ Cardiovasc Imaging. 2018 Sep; 11(9):e007813.

41 Flügge AK, Wasmer $K$, Orwat $S$, AbdulKhaliq H, Helm PC, Bauer U, et al.; German Competence Network for Congenital Heart Defects Investigators. Cardiac resynchronization therapy in congenital heart disease: Results from the German National Register for Congenital Heart Defects. Int J Cardiol. 2018 Dec;273:108-11.

42 Moore JP, Cho D, Lin JP, Lluri G, Reardon LC, Aboulhosn JA, et al. Implantation techniques and outcomes after cardiac resynchronization therapy for congenitally corrected transposition of the great arteries. Heart Rhythm. 2018 Dec;15(12):1808-15.

43 Karpawich PP, Bansal N, Samuel S, Sanil Y, Zelin K. 16 Years of Cardiac Resynchronization Pacing Among Congenital Heart Disease Patients: Direct Contractility (dP/dtmax) Screening When the Guidelines Do Not Apply. JACC Clin Electrophysiol. 2017 Aug; 3(8):830-41.

44 Anjewierden S, Aziz PF. Resynchronization Therapy for Patients with Congenital Heart Disease: Are We Ready for Prime Time? Curr Cardiol Rep. 2018 Jul;20(9):75.

45 Breithardt OA, Sinha AM, Schwammenthal E, Bidaoui N, Markus KU, Franke A, et al. Acute effects of cardiac resynchronization therapy on functional mitral regurgitation in advanced systolic heart failure. J Am Coll Cardiol. 2003 Mar;41(5):765-70.

46 Cleland JG, Daubert JC, Erdmann E, Freemantle N, Gras D, Kappenberger L, et al. The effect of cardiac resynchronization on morbidity and mortality in heart failure. $\mathrm{N}$ Engl J Med. 2005;352(15):1539-49.

47 Cabrera-Bueno F, García-Pinilla JM, PeñaHernández J, Jiménez-Navarro M, GómezDoblas JJ, Barrera-Cordero A, et al. Repercussion of functional mitral regurgitation on reverse remodelling in cardiac resynchronization therapy. Europace. 2007 Sep;9(9): 757-61.

48 Onishi T, Onishi T, Marek JJ, Ahmed M, Haberman SC, Oyenuga O, et al. Mechanistic features associated with improvement in mitral regurgitation after cardiac resynchronization therapy and their relation to long-term patient outcome. Circ Heart Fail. 2013 Jul; 6(4):685-93.

49 Binda C, Menet A, Appert L, Ennezat PV, Delelis F, Castel AL, et al. Time course of secondary mitral regurgitation in patients with heart failure receiving cardiac resynchronization therapy: impact on long-term outcome beyond left ventricular reverse remodelling. Arch Cardiovasc Dis. 2018 May;111(5):32031.

50 Upadhyay GA, Steinberg JS. Managing atrial fibrillation in the CRT patient: controversy or consensus? Heart Rhythm. 2012 Aug;9(8 Suppl):S51-9.

51 Gianni C, Di Biase L, Mohanty S, Gökoğlan Y, Güneş MF, Al-Ahmad A, et al. How to improve cardiac resynchronization therapy benefit in atrial bibrillation patients: pulmonary vein isolation (and beyond). Heart Fail Clin. 2017 Jan;13(1):199-208.

52 Jeevanantham V, Turagam M, Shanberg D, Reddy M, Atoui M, Daubert JP, et al. Cardiac Resynchronization Therapy prevents progression of renal failure in heart failure patients. Indian Pacing Electrophysiol J. 2016 Jul - Aug;16(4):115-9.

53 Goldenberg I, Moss AJ, McNitt S, Barsheshet A, Gray D, Andrews ML, et al.; Multicenter Automatic Defibrillator Implantation TrialCardiac Resynchronization Therapy Investigators. Relation between renal function and response to cardiac resynchronization therapy in Multicenter Automatic Defibrillator Implantation Trial-Cardiac Resynchronization Therapy (MADIT-CRT). Heart Rhythm. 2010 Dec;7(12):1777-82.

54 Sun H, Guan Y, Wang L, Zhao Y, Lv H, Bi X, et al. Influence of diabetes on cardiac resynchronization therapy in heart failure patients: a meta-analysis. BMC Cardiovasc Disord. 2015 Mar; 15(1):25.

55 Kirubakaran S, Ladwiniec A, Arujuna A, Ginks M, McPhail M, Bostock J, et al. Male gender and chronic obstructive pulmonary disease predict a poor clinical response in patients undergoing cardiac resynchronisation therapy. Int J Clin Pract. 2011 Mar;65(3): 281-8.

56 Ruwald MH. Co-Morbidities and Cardiac Resynchronization Therapy: When Should They Modify Patient Selection? J Atr Fibrillation. 2015 Jun;8(1):1238.

57 Brouwers C, Versteeg H, Meine M, Heijnen CJ, Kavelaars AM, Pedersen SS, et al. Association between brain natriuretic peptide, markers of inflammation and the objective and subjective response to cardiac resynchronization therapy. Brain Behav Immun. 2014 Aug; $40: 211-8$ 
58 Truong QA, Januzzi JL, Szymonifka J, Thai WE, Wai B, Lavender Z, et al. Coronary sinus biomarker sampling compared to peripheral venous blood for predicting outcomes in patients with severe heart failure undergoing cardiac resynchronization therapy: the BIOCRT study. Heart Rhythm. 2014 Dec; 11(12):2167-75.

59 Beaudoin J, Singh JP, Szymonifka J, Zhou Q, Levine RA, Januzzi JL, et al. Novel heart failure biomarkers predict improvement of mitral regurgitation in patients receiving cardiac resynchronization therapy-the BIOCRT Study. Can J Cardiol. 2016 Dec;32(12):147884.

60 Lin J, Buhr KA, Kipp R. Effect of PR Interval on Outcomes Following Cardiac Resynchronization Therapy: A Secondary Analysis of the COMPANION Trial. J Cardiovasc Electrophysiol. 2017 Feb;28(2):185-91.

61 Hsing JM, Selzman KA, Leclercq C, Pires LA, McLaughlin MG, McRae SE, et al. Paced left ventricular QRS width and ECG parameters predict outcomes after cardiac resynchronization therapy: PROSPECT-ECG substudy. Circ Arrhythm Electrophysiol. 2011 Dec;4(6): 851-7.

62 Sinner GJ, Gupta VA, Seratnahaei A, Charnigo RJ, Darrat YH, Elayi SC, et al. Atrioventricular dyssynchrony from empiric device settings is common in cardiac resynchronization therapy and adversely impacts left ventricular morphology and function. Echocardiography. 2017 Apr;34(4):496-503.

63 Meluzín J, Novák M, Müllerová J, Krejcí J, Hude P, Eisenberger M, et al. A fast and simple echocardiographic method of determination of the optimal atrioventricular delay in patients after biventricular stimulation. Pacing Clin Electrophysiol. 2004 Jan;27(1):5864.

64 van Gelder BM, Bracke FA, Meijer A, Lakerveld LJ, Pijls NH. Effect of optimizing the VV interval on left ventricular contractility in cardiac resynchronization therapy. Am J Cardiol. 2004 Jun;93(12):1500-3.

65 Bogaard MD, Meine M, Doevendans PA. Programmed versus effective VV delay during CRT optimization: when what you see is not what you get. Pacing Clin Electrophysiol. 2013 Apr;36(4):403-9.

66 Stankovic I, Belmans A, Prinz C, Ciarka A, Maria Daraban A, Kotrc M, et al. The association of volumetric response and long-term survival after cardiac resynchronization therapy. Eur Heart J Cardiovasc Imaging. 2017 Oct;18(10):1109-17.

67 Stankovic I, Prinz C, Ciarka A, Daraban AM, Mo Y, Aarones M, et al. Long-Term Outcome After CRT in the Presence of Mechanical Dyssynchrony Seen with Chronic RV Pacing or Intrinsic LBBB. JACC Cardiovasc Imaging. 2017 Oct;10(10 10 Pt A):1091-9.

68 Weigand S, Karl M, Brkić A, Lennerz C, Grebmer C, Blažek P, et al. The impact of multipole pacing on left ventricular function in patients with cardiac resynchronization therapy - A real-time three-dimensional echocardiography approach. Int J Cardiol. 2018 Dec;272: 238-43.

69 Vondrak J, Marek D, Vecera J, Benesova K, Matejka J. Cardiac resynchronisation therapy optimisation of interventricular delay by the systolic dyssynchrony index: a comparative, randomised, 12-month follow-up study. Hellenic J Cardiol. 2017. doi: 10.1016/j. hjc.2017.11.003.

70 Höke U, Bax JJ, Delgado V, Ajmone Marsan N. Assessment of left ventricular dyssynchrony by three-dimensional echocardiography: prognostic value in patients undergoing cardiac resynchronization therapy. J Cardiovasc Electrophysiol. 2018 May;29(5):780-7.

71 Tatsumi K, Tanaka H, Tsuji T, Kaneko A, Ryo $\mathrm{K}$, Yamawaki K, et al. Strain dyssynchrony index determined by three-dimensional speckle area tracking can predict response to cardiac resynchronization therapy. Cardiovasc Ultrasound. 2011 Apr;9(1):11.

72 Vecera J, Penicka M, Eriksen M, Russell K, Bartunek J, Vanderheyden M, et al. Wasted septal work in left ventricular dyssynchrony: a novel principle to predict response to cardiac resynchronization therapy. Eur Heart J Cardiovasc Imaging. 2016 Jun;17(6):624-32.

73 Galli E, Leclercq C, Hubert A, Bernard A, Smiseth OA, Mabo P, et al. Role of myocardial constructive work in the identification of responders to CRT. Eur Heart J Cardiovasc Imaging. 2018 Sep;19(9):1010-8.

74 Galli E, Leclercq C, Fournet M, Hubert A, Bernard A, Smiseth OA, et al. Value of Myocardial Work Estimation in the Prediction of Response to Cardiac Resynchronization Therapy. J Am Soc Echocardiogr. 2018 Feb; 31(2):220-30.

75 Gilewski W, Błażejewski J, Karasek D, Banach J, Wołowiec $€$, Płońska-Gościniak E, et al. Are changes in heart rate, observed during dobutamine stress echocardiography, associated with a response to cardiac resynchronisation therapy in patients with severe heart failure? Results of a multicentre ViaCRT study. Kardiol Pol. 2018;76(3):611-7.

76 Pugliese NR, Fabiani I, Mandoli GE, Guarini G, Galeotti GG, Miccoli M, et al. Echo-derived peak cardiac power output-to-left ventricular mass with cardiopulmonary exercise testing predicts outcome in patients with heart failure and depressed systolic function. Eur Heart J Cardiovasc Imaging. 2018 Nov. https://doi.org/10.1093/ehjci/jey172.

77 Guazzi M, Bandera F, Ozemek C, Systrom D, Arena R. Cardiopulmonary Exercise Testing: What Is its Value? J Am Coll Cardiol. 2017 Sep;70(13):1618-36.

78 Wong JA, Yee R, Stirrat J, Scholl D, Krahn $\mathrm{AD}$, Gula LJ, et al. Influence of pacing site characteristics on response to cardiac resynchronization therapy. Circ Cardiovasc Imaging. 2013 Jul;6(4):542-50.

79 Antoniadis AP, Sieniewicz B, Gould J, Porter $\mathrm{B}$, Webb J, Claridge S, et al. Updates in cardiac resynchronization therapy for chronic heart failure: review of multisite pacing. Curr Heart Fail Rep. 2017 Aug;14(5):376-83.

80 Markstad H, Bakos Z, Ostenfeld E, Geijer M, Carlsson M, Borgquist R. Preoperative CT of cardiac veins for planning left ventricular lead placement in cardiac resynchronization therapy. Acta Radiol. 2018. doi: 10.1177/0284185118803796

81 Antoniadis AP, Behar JM, Sieniewicz B, Gould J, Niederer S, Rinaldi CA. A comparison of the different features of quadripolar left ventricular pacing leads to deliver cardiac resynchronization therapy. Expert Rev Med Devices. 2017 Sep;14(9):697-706.

82 Tomasi C, Corsi C, Turco D, Severi S. An exploratory study on coronary sinus lead tip three-dimensional trajectory changes in cardiac resynchronization therapy. Heart Rhythm. 2013 Sep;10(9):1360-7.

83 Miranda RI, Nault M, Johri A, Simpson CS, Michael KA, Abdollah H, et al. Maximal electric separation-guided placement of right ventricular lead improves responders in cardiac resynchronization defibrillator therapy. Circ Arrhythm Electrophysiol. 2012 Oct;5(5):927-32.

84 Su H, Bao P, Chen KY, Yan J, Xu J, Yu F, et al. Influence of the Right Ventricular Lead Location on Ventricular Arrhythmias in Cardiac Resynchronization Therapy. Chin Med J (Engl). 2018 Oct;131(20):2402-9.

85 Lercher P, Lunati M, Rordorf R, Landolina M, Badie N, Qu F, et al. Long-term reverse remodeling by cardiac resynchronization therapy with MultiPoint Pacing: a feasibility study of noninvasive hemodynamics-guided device programming. Heart Rhythm. 2018. doi: 10.1016/j.hrthm.2018.06.032.

86 Sharma PS, Vijayaraman P. His Bundle Pacing Or Biventricular Pacing For Cardiac Resynchronization Therapy In Heart Failure: Discovering New Methods For An Old Problem. J Atr Fibrillation. 2016 Dec;9(4):1501.

87 Mazurek M, Jędrzejczyk-Patej E, Lenarczyk R, Liberska A, Przybylska-Siedlecka K, Kozieł $\mathrm{M}$, et al. Do we need to monitor the percentage of biventricular pacing day by day? Int $J$ Cardiol. 2016 Oct;221:81-9.

88 Jin H, Gu M, Hua W, Fan XH, Niu HX, Ding LG, et al. Predictors of super-response to cardiac resynchronization therapy: the significance of heart failure medication, pre-implant left ventricular geometry and high percentage of biventricular pacing. J Geriatr Cardiol. 2017 Dec;14(12):737-42.

89 Duncker D, Delnoy PP, Nägele H, Mansourati J, Mont L, Anselme F, et al. First clinical evaluation of an atrial haemodynamic sensor lead for automatic optimization of cardiac resynchronization therapy. Europace. 2016 May;18(5):755-61.

90 Brugada J, Delnoy PP, Brachmann J, Reynolds D, Padeletti L, Noelker G, et al.; RESPOND CRT Investigators. Contractility sensor-guided optimization of cardiac resynchronization therapy: results from the RESPOND-CRT trial. Eur Heart J. 2017 Mar; 38(10):730-8. 
91 Sermesant M, Chabiniok R, Chinchapatnam P, Mansi T, Billet F, Moireau P, et al. Patientspecific electromechanical models of the heart for the prediction of pacing acute effects in CRT: a preliminary clinical validation. Med Image Anal. 2012 Jan;16(1):201-15.

92 Panthee N, Okada J, Washio T, Mochizuki Y, Suzuki R, Koyama H, et al. Tailor-made heart simulation predicts the effect of cardiac resynchronization therapy in a canine model of heart failure. Med Image Anal. 2016 Jul;31: 46-62.

93 Østvik A, Smistad E, Aase SA, Haugen BO, Lovstakken L. Real-Time Standard View Classifcation in Transthoracic Echocardiography Using Convolutional Neural Net- works. Ultrasound Med Biol. 2019 Feb;45(2): 374-384.

94 Leng S, Yang X, Zhao X, Zeng Z, Su Y, Koh AS, et al. Computational Platform Based on Deep Learning for Segmenting Ventricular Endocardium in Long-axis Cardiac MR Imaging. Conf Proc IEEE Eng Med Biol Soc. 2018 Jul;2018:4500-3.

95 Vukicevic M, Mosadegh B, Min JK, Little SH. Cardiac 3D printing and its future directions. JACC Cardiovasc Imaging. 2017 Feb;10(2): 171-84.

96 Chen Z, Niederer S, Shanmugam N, Sermesant M, Rinaldi CA. Cardiac computational modeling of ventricular tachycardia and cardiac resynchronization therapy: a clinical perspective. Minerva Cardioangiol. 2017 Aug;65(4):380-97.

97 Warriner DR, Jackson T, Zacur E, Sammut E, Sheridan P, Hose DR, et al. An Asymmetric Wall-Thickening Pattern Predicts Response to Cardiac Resynchronization Therapy. JACC Cardiovasc Imaging. 2018 Oct;11(10): $1545-6$.

98 Lumens J, Tayal B, Walmsley J, DelgadoMontero A, Huntjens PR, Schwartzman D, et al. Differentiating Electromechanical from Non-Electrical Substrates of Mechanical Discoordination to Identify Responders to Cardiac Resynchronization Therapy. Circ Cardiovasc Imaging. 2015 Sep;8(9): e003744. 